\title{
Prediction of Functional Overreaching From Subjective Fatigue and Readiness to Train After Only 3 Days of Cycling
}

\author{
Twan ten Haaf, Selma van Staveren, Erik Oudenhoven, Maria F. Piacentini, Romain Meeusen, \\ Bart Roelands, Leo Koenderman, Hein A.M. Daanen, Carl Foster, and Jos J. de Koning
}

\begin{abstract}
Purpose: To investigate whether monitoring of easily measurable stressors and symptoms can be used to distinguish early between acute fatigue (AF) and functional overreaching (FOR). Methods: The study included 30 subjects (11 female, 19 male; age $40.8 \pm 10.8 \mathrm{y}, \mathrm{VO}_{2} \max 51.8 \pm 6.3 \mathrm{~mL} \cdot \mathrm{kg}^{-1} \cdot \mathrm{min}^{-1}$ ) who participated in an 8-d cycling event over $1300 \mathrm{~km}$ with 18,500 climbing meters. Performance was measured before and after the event using a maximal incremental test. Subjects with decreased performance after the event were classified as FOR, others as AF. Mental and physical well-being, internal training load, resting heart rate, temperature, and mood were measured daily during the event. Differences between AF and FOR were analyzed using mixed-model ANOVAs. Logistic regression was used to determine the best predictors of FOR after 3 and $6 \mathrm{~d}$ of cycling. Results: Fifteen subjects were classified as FOR and 14 as AF (1 excluded). Although total group changes were observed during the event, no differences between AF and FOR were found for individual monitoring parameters. The combination of questionnaire-based changes in fatigue and readiness to train after $3 \mathrm{~d}$ cycling correctly predicted $78 \%$ of the subjects as AF or FOR (sensitivity $=$ $79 \%$, specificity $=77 \%$ ). Conclusions: Monitoring changes in fatigue and readiness to train, using simple visual analog scales, can be used to identify subjects likely to become FOR after only $3 \mathrm{~d}$ of cycling. Hence, we encourage athlete support staff to monitor not only fatigue but also the subjective integrated mental and physical readiness to perform.
\end{abstract}

Keywords: overtraining, internal training load, mood disturbance, resting heart rate, POMS

Overtraining is a process of intensified training and insufficient rest, with possible outcomes of functional (FOR) or nonfunctional overreaching (NFOR) or overtraining syndrome (OTS). ${ }^{1,2}$ FOR might be a normal part of the fitness-fatigue adaptive continuum and is often deliberately induced in training camps to improve performance. However, Aubry et $\mathrm{al}^{3,4}$ demonstrated that the supercompensation effect of performance was smaller in FOR than in acutely fatigued (AF) athletes after a 3 -week training camp. Hausswirth et $\mathrm{al}^{5}$ showed that FOR athletes experienced disturbed sleep and had a higher incidence of illness compared with AF. Moreover, FOR precedes NFOR/OTS, which is the part of the overtraining continuum where the more severe and persistent symptoms such as psychological distress and/or endocrine disturbances occur. ${ }^{1,2}$ Prevention of NFOR/ OTS is therefore of utmost importance. For these reasons, athletes and coaches might want to be aware of FOR during competition and training camps. Hence, the focus of this study is on the distinction between AF and FOR to be able to early identify FOR.

Since there is no known single cause and mechanism of the overtraining continuum, monitoring of stressors and symptoms seems key for prevention. Monitoring tools must be easy to use and inexpensive, give quick results, and be able to sense changes before

ten Haaf, Oudenhoven, Daanen, and de Koning are with the Dept of Human Movement Sciences, MOVE Research Inst Amsterdam, Amsterdam, the Netherlands. van Staveren and Koenderman are with the Dept of Respiratory Medicine, University Medical Center Utrecht, Utrecht, the Netherlands. Piacentini is with the University of Rome "Foro Italico," Rome, Italy. Meeusen and Roelands are with the Human Physiology Research Group. Vrije Universiteit Brussel, Brussels, Belgium. Foster is with the Dept of Exercise and Sports Science, University of Wisconsin-La Crosse, La Crosse, WI. Address author correspondence to Twan ten Haaf at tpg.ten.haaf@vu.nl. symptoms occur. ${ }^{1,2}$ Training load, mood disturbances, resting heart rate, and the combination of heart-rate recovery with perceived fatigue fit these criteria and are often used in monitoring studies. ${ }^{6-9}$ Monitoring of the external training load, quantified by the training volume and intensity, is insufficient because many circumstances can influence the ability of an athlete to handle a given external load. ${ }^{10}$ The internal load is the physiological and psychological stress that results from the external load. One of the most widely used methods to quantify the internal load is the session rating of perceived exertion (SRPE). ${ }^{11}$

Studies on the overtraining spectrum generally have crosssectional designs with small sample sizes, because the impact of symptoms and lack of effective therapies make it hard to apply overtraining as an intervention. ${ }^{12}$ These studies do not provide insight in the development of the overtraining continuum. Therefore, the aim of this study was to investigate whether monitoring of easily measurable stressors and symptoms can be used to early distinguish between AF and FOR.

In this study the development of FOR was investigated in amateur cyclists that participated in the Tour for Life (TFL). The TFL is an 8-day recreational fundraising cycling tour from Italy to the Netherlands (1300 km with 18,500 climbing meters) involving mostly middle-aged athletes. The TFL model allowed us to study the development of FOR in a relatively large population.

\section{Methods}

\section{Subjects}

Thirty (11 female, 19 male) recreational cyclists participated in the study (mean \pm SD age $40.8 \pm 10.8 \mathrm{y}, \mathrm{BMI} 23.5 \pm 2.1 \mathrm{~kg} / \mathrm{m}^{2}$ ). At baseline the $\mathrm{VO}_{2} \max$ was $51.8 \pm 6.3 \mathrm{~mL} \cdot \mathrm{kg}^{-1} \cdot \mathrm{min}^{-1}$ and peak 
power output $4.12 \pm 0.57 \mathrm{~W} / \mathrm{kg}$. Subjects reported an estimated training volume of $144 \pm 46 \mathrm{~km} /$ wk during preparation. The subjects were categorized in performance levels 1 (4\%), 2 (57\%), 3 (25\%), and $4(14 \%)$ according to the $\mathrm{VO}_{2}$ max-based athlete-classification norms of De Pauw ${ }^{13}$ and Decroix. ${ }^{14}$ The subjects were relatively fit for their age, reflected by a $\mathrm{VO}_{2}$ max of $148 \% \pm 17 \%$ relative to the Jones norm ${ }^{15}$ (Table 1).

Table 1 Baseline Characteristics (Mean \pm SD) for Acutely Fatigued (AR) and Functionally Overreached (FOR) Subjects

\begin{tabular}{lccc}
\hline & AF $(\mathbf{n}=\mathbf{1 4})$ & FOR $(\mathbf{n}=15)$ & $P$ \\
\hline Gender $(\mathrm{M} / \mathrm{F})$ & $11 / 3$ & $7 / 8$ & .13 \\
Age $(\mathrm{y})$ & $42.6 \pm 11.0$ & $39.1 \pm 10.7$ & .39 \\
Body-mass index $\left(\mathrm{kg} / \mathrm{m}^{2}\right)$ & $24.0 \pm 1.7$ & $23.0 \pm 2.3$ & .22 \\
$\mathrm{VO}_{2} \mathrm{max}\left(\mathrm{mL} \cdot \mathrm{min}^{-1} \cdot \mathrm{kg}^{-1}\right)$ & $51.6 \pm 6.3$ & $52.3 \pm 6.1$ & .76 \\
Peak power output $(\mathrm{W} / \mathrm{kg})$ & $4.2 \pm 0.6$ & $4.0 \pm 0.5$ & .50 \\
\hline
\end{tabular}

An introductory meeting was organized during which the purpose, study design, and measurements were explained to the subjects. Before the first measurements, participants gave written informed consent. The study was conducted in accordance with the Declaration of Helsinki and approved by the institutional ethical committee.

\section{Design}

This observational study was designed around the TFL. The subjects cycled together with about 400 contestants from Italy to the Netherlands in 8 days. They slept in tents at camping sites. The start of the stages was between 7:00 and 8:00 AM and the finish between 4:00 and 7:30 PM, depending on the rider's fitness level and the length of the stage. The external training load of each stage is shown in Table 2. Every morning resting heart rate and rectal temperature were measured. Within 30 minutes of finishing stages 1 to 7 subjects reported the session rating of perceived exertion (sRPE) ${ }^{11,16}$ and completed a 7 -item diary ${ }^{17}$ on subjective physical and mental well-being. It was practically impossible to collect data after this

Table 2 External and Internal Training Load per Stage

\begin{tabular}{|c|c|c|c|c|c|}
\hline Stage & Distance (km) & Climbing (m) & Duration (min) & SRPE (AU) & Load $\left(A U \times 10^{3}\right)$ \\
\hline 1 & 110 & 2800 & & & \\
\hline $\mathrm{AF}$ & & & $389 \pm 62$ & $7.9 \pm 1.0$ & $3.1 \pm 0.7$ \\
\hline FOR & & & $386 \pm 68$ & $7.6 \pm 1.5$ & $2.9 \pm 0.7$ \\
\hline 2 & 160 & 4200 & & & \\
\hline $\mathrm{AF}$ & & & $616 \pm 75$ & $7.4 \pm 2.1$ & $4.6 \pm 1.5$ \\
\hline FOR & & & $569 \pm 146$ & $7.9 \pm 1.8$ & $4.4 \pm 1.4$ \\
\hline 3 & 175 & 2900 & & & \\
\hline $\mathrm{AF}$ & & & $586 \pm 88$ & $7.1 \pm 1.8$ & $4.3 \pm 1.5$ \\
\hline FOR & & & $543 \pm 163$ & $6.8 \pm 2.7$ & $4.0 \pm 1.8$ \\
\hline 4 & 190 & 1900 & & & \\
\hline $\mathrm{AF}$ & & & $555 \pm 80$ & $7.3 \pm 2.4$ & $4.1 \pm 1.6$ \\
\hline FOR & & & $509 \pm 159$ & $5.7 \pm 2.7$ & $3.2 \pm 1.8$ \\
\hline 5 & 129 & 2450 & & & \\
\hline $\mathrm{AF}$ & & & $405 \pm 137$ & $5.3 \pm 2.4$ & $2.3 \pm 1.1$ \\
\hline FOR & & & $434 \pm 80$ & $6.9 \pm 1.4^{*}$ & $3.0 \pm 1.0$ \\
\hline 6 & 175 & 900 & & & \\
\hline $\mathrm{AF}$ & & & $417 \pm 62$ & $6.0 \pm 2.1$ & $2.5 \pm 0.9$ \\
\hline FOR & & & $411 \pm 59$ & $5.5 \pm 2.4$ & $2.2 \pm 1.0$ \\
\hline 7 & 215 & 2200 & & & \\
\hline $\mathrm{AF}$ & & & $554 \pm 70$ & $7.1 \pm 1.9$ & $4.0 \pm 1.2$ \\
\hline FOR & & & $561 \pm 96$ & $7.7 \pm 1.2$ & $4.3 \pm 0.9$ \\
\hline 8 & 110 & 1200 & & & \\
\hline $\mathrm{AF}$ & & & & No data available & \\
\hline FOR & & & & No data available & \\
\hline Total & 1,264 & 18,550 & & & \\
\hline $\mathrm{AF}$ & & & $3522 \pm 397$ & $6.9 \pm 1.5$ & $24.8 \pm 6.7$ \\
\hline FOR & & & $3414 \pm 523$ & $6.9 \pm 1.0$ & $24.1 \pm 5.7$ \\
\hline
\end{tabular}

Note: for practical reasons no data could be collected after stage 8 . Abbreviations: AF, acutely fatigued; FOR, functionally overreached.

$* P<.05$ for difference between $\mathrm{AF}$ and $\mathrm{FOR}$. 
last stage. The 32-item Dutch version of the Profile of Mood States questionnaire (POMS $)^{18}$ was filled out the evening before the first stage (start) and after stage 3 (halfway) and stage 6 (end) of the TFL.

Subjects visited the laboratory 12 to 17 days before and 5 to 8 days and 33 to 36 days after the TFL (Figure 1). During each laboratory visit the subjects performed 2 maximal incremental tests on a cycling ergometer with 4 hours between the starts of both tests. ${ }^{19}$

\section{Methodology}

The laboratory exercise tests started with cycling (Excalibur Sport, Lode Medical Technology, Groningen, The Netherlands, or; Ergomedic 839E, Monark Exercise AB, Vansbro, Sweden) at $80 \mathrm{~W}$ for 3 minutes. Power increased $40 \mathrm{~W}$ for men and $30 \mathrm{~W}$ for women every 3 minutes. The subjects cycled at a freely chosen pedaling frequency. The test was stopped when subjects were unable to maintain a pedaling frequency above $60 \mathrm{rpm}$, despite strong verbal encouragement. Peak power output was defined as the average power output over the last 3 minutes of the exercise test. Each subject performed the tests on the same ergometer and at the same time of the day. Saddle and handle bar height were measured after the first test and the same settings were used in subsequent tests.

Subjects rated their physical and mental well-being by means of a visual analog scale (VAS) for 7 items after stage 1 to 7 . Items included sleep quality, general mental well-being, general physical well-being, readiness to train, muscle soreness, fatigue, and attractiveness of the training day. ${ }^{17}$

SRPE was determined by asking individuals to rate the intensity of the stage on a VAS. SRPE and exercise time were used to calculate load, monotony, and strain. ${ }^{20}$ The product of the SRPE (0-10) and stage duration ( $\mathrm{min}$ ) was termed the daily load. Total load was calculated for the first half of the TFL (stage 1-3) and for all stages by summation of the daily loads. Monotony and strain were calculated over all stages. Monotony was computed by dividing the average daily load by the SD of the daily load. Strain was calculated as the product of total load and monotony.
Resting heart rate was measured with the subject's own heartrate monitor and rectal temperature with a standard commercial thermometer every day during TFL directly after waking up. The validity of the thermometers was checked using a Pt100 digital temperature indicator (P650, Dostmann Electronic, WertheimReicholzheim, Germany).

POMS subscales (vigor, anger, fatigue, depression, tension) were calculated. In addition total mood disturbance (TMD) was calculated by the sum of anger, fatigue, depression and tension and subtracting the vigor score. In addition, the energy index (EI) was calculated by subtracting fatigue from vigor. ${ }^{21}$

Changes between start and halfway TFL, and between start and end TFL were calculated for POMS, 7-item diary, resting heart rate, and core temperature. All monitoring data were collected using paper and pencil and digitalized using double-entry method.

\section{Classification of Subjects}

FOR is characterized by a temporary performance decrement. In line with previous research the smallest worthwhile change (SWC) was used as a FOR threshold. ${ }^{3,4}$ The SWC was calculated by $0.3 \times$ the coefficient of variation ${ }^{22}$ of peak power output between the 2 exercise tests before the TFL (T1, T2). The pre-TFL versus postTFL performance decrement was used because athletes are able to recover from FOR in days to weeks and the training volume was not set in the follow-up period. Subjects whose pre-TFL versus post-TFL performance decrement was larger than the smallest worthwhile change on both exercise tests (ie, T1-T3 $>$ T1 $\times$ SWC and T2-T4 $>$ T2 $\times$ SWC) were classified as FOR. All other subjects were classified as acutely fatigued (AF).

\section{Statistical Analysis}

Missing values of subjects with maximally one missing value per monitoring tool were imputed. For the POMS the missing value was replaced with the individual mean of the subscale. For the

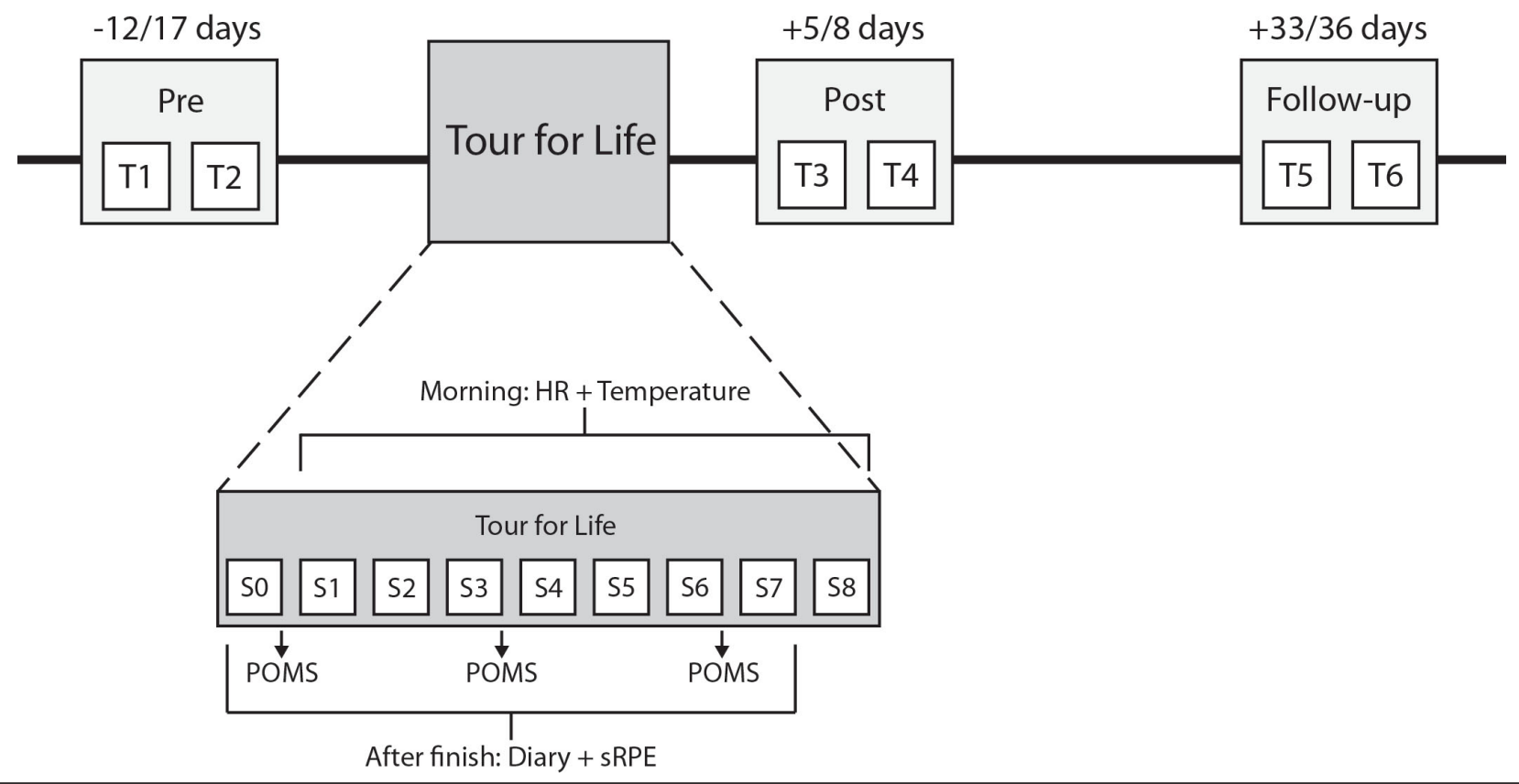

Figure 1 - Study design. Two maximal incremental tests were performed before and twice after an 8-day cycling event. Abbreviations: T, maximal incremental tests; S, stage; HR, resting heart rate; POMS, Profile of Mood States; sRPE, session rating of perceived exertion. 
other measures the ratio between the subject's value and the other subjects for the nonmissing stages was used. In total 44 out of 5250 data entries were imputed $(0.8 \%)$.

Differences in total load, monotony, and strain were assessed using independent $t$ tests. Mixed-model analyses of variance with stage as a within-subject factor and class (AF/FOR) as a between-subjects factor were performed for the change in peak power output and all daily monitoring measures. Interactions were followed up with 1-way ANOVAs if they were significant at the $5 \%$ level.

Binary logistic-regression analysis was carried out to identify a combination of monitoring measures that predict FOR. Analysis was carried out for changes halfway and for changes between start and end of the TFL. First, a preselection of predictors was performed by testing all monitoring measures individually in logistic regression (ie, diary items, load, monotony, strain, resting heart rate, rectal temperature, POMS subscales, TMD, EI). The 3 measures with the lowest $P$ value for the Wald statistic were together inserted in a backward-method logistic regression with class (AF/FOR) as the outcome variable. Assumptions of linearity and multicollinearity of the predictors were checked and residuals were analyzed for outliers and influential cases.

Magnitude-based inferences were described as advised by Hopkins and colleagues. ${ }^{23}$ Statistical analysis was performed using SPSS (IBM Corp, IBM SPSS Statistics for Windows version 23.0. Armonk, NY).

\section{Results}

\section{Classification}

One subject was excluded from analysis because of asthmatic symptoms during the post-TFL exercise tests. The coefficient of variation of peak power output during pre-TFL exercise tests was $1.6 \%$, so the SWC was $0.5 \%$. Based on the described criteria this resulted in 15 subjects being classified as FOR and 14 as AF (Figure 2). Characteristics of the classes are displayed in Table 1.

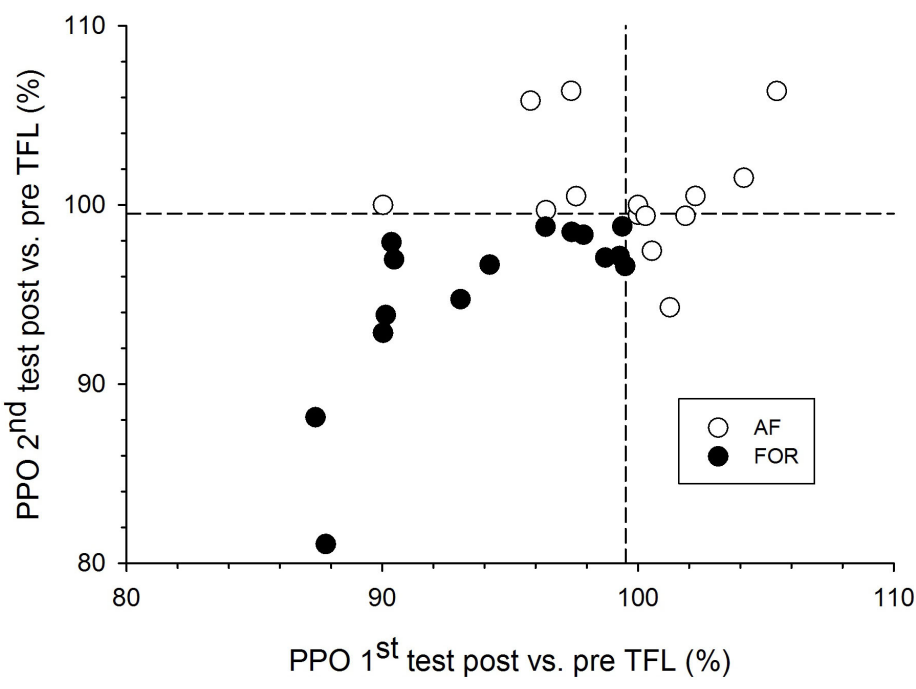

Figure 2 - Classification of acutely fatigued (AF) and functionally overreached (FOR) subjects. Subjects whose performance decrement on both (T1 vs T3 and T4 vs T2, Figure 1) exercise tests was larger than the smallest worthwhile change (dashed lines) were classified as FOR. Abbreviations: PPO, peak power output; TFL, Tour for Life.

\section{Comparing the Means of AF and FOR}

The performance decrement post-TFL was almost certainly larger for FOR $(-16.5 \pm 11.9 \mathrm{~W})$ compared with AF $(-0.5 \pm 7.5 \mathrm{~W})(P<$ $\left..01, \eta^{2}=.41\right)$, and probably still larger at follow-up $(-13.0 \pm 18.0$ vs $-3.1 \pm 13.6 \mathrm{~W}$ respectively, $P=.12, \eta^{2}=.09$ ) (Figure 3 ).

On a group level, readiness to train was significantly lower after stages 2, 3 and 7 compared with baseline (Figure 4 A). Subjects reported higher fatigue scores than at baseline from stage 3 to 7 (Figure 4 B). Muscle soreness after all stages was higher than at baseline. However, none of the diary items revealed a difference between AF and FOR (data not shown).

Total cycling time of stage 1 to 7 was $57.8 \pm 7.7$ hours. The only significant difference between the means of FOR and AF was in the sRPE at stage $5(6.9 \pm 1.4$ AU vs $5.3 \pm 2.4$ AU respectively, $P=.04, r=.43$ ) (Figure $4 \mathrm{C}$ ). There were no differences between $\mathrm{AF}$ and FOR in total load $\left(2.5 \times 10^{4} \pm 0.7 \times 10^{4}\right.$ vs $2.4 \times 10^{4} \pm 0.6$ $\left.\times 10^{4} \mathrm{AU}, P=.75\right)$, monotony $(3.6 \pm 1.2 \mathrm{AU}$ vs. $3.0 \pm 1.1 \mathrm{AU}, P$ $=.19)$, and strain $\left(9.1 \times 10^{4} \pm 3.6 \times 10^{4}\right.$ vs. $7.5 \times 10^{4} \pm 3.2 \times 10^{4}$ AU, $P=.22$ ).

Resting heart rate was significantly higher for the total group in stages 3, 4 and 5 but returned to baseline level near the end of the TFL (Figure 4 D). No differences between AF and FOR were observed. The observed effect of class on rectal temperature was probably small (AF: $35.9 \pm 0.1^{\circ} \mathrm{C}$, FOR: $36.3 \pm 0.1^{\circ} \mathrm{C}, P=.06, \eta^{2}$ $=.14$ ) and did not change during the TFL (data not shown).

None of the POMS scales revealed a difference between AF and FOR (Table 3). On total group level, fatigue, anger and total mood disturbance increased significantly during the TFL. Vigor, tension, and energy index decreased significantly after the start.

\section{Logistic-Regression Analysis}

A logistic-regression model (Table 4) including change in fatigue and readiness to train (both VAS) halfway through the TFL predicted $78 \%$ of the subjects in the correct class (sensitivity $=79 \%$, specificity $=77 \%$ ). The individual data points for these 2 factors are shown in Figure 5. The sensitivity and specificity were lower when only fatigue $(67 \%, 36 \%)$ or readiness $(60 \%, 71 \%)$ was inserted in the analysis.

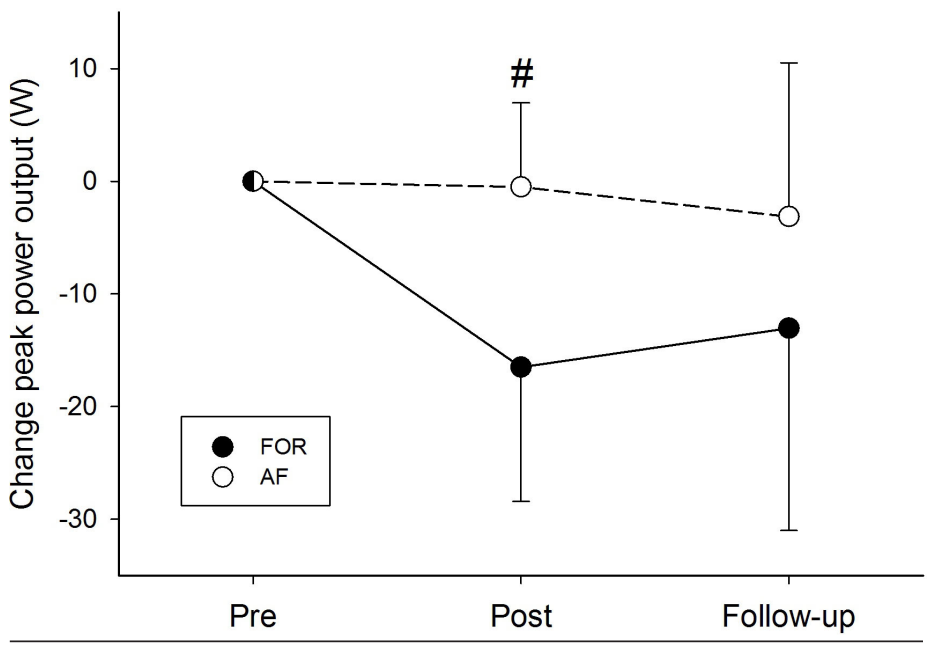

Figure 3 - Change in peak power output for the acutely fatigued (AF) and functionally overreached (FOR) subjects (mean \pm SD). \#Different from FOR $(P<.05)$. 
A

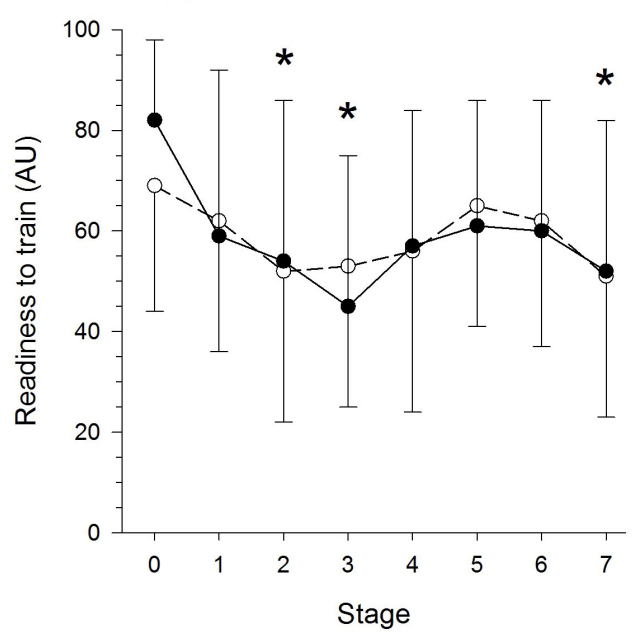

C

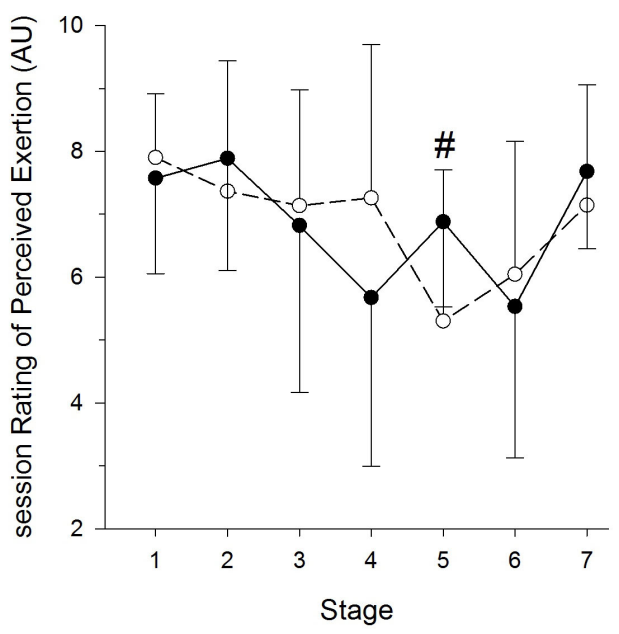

B

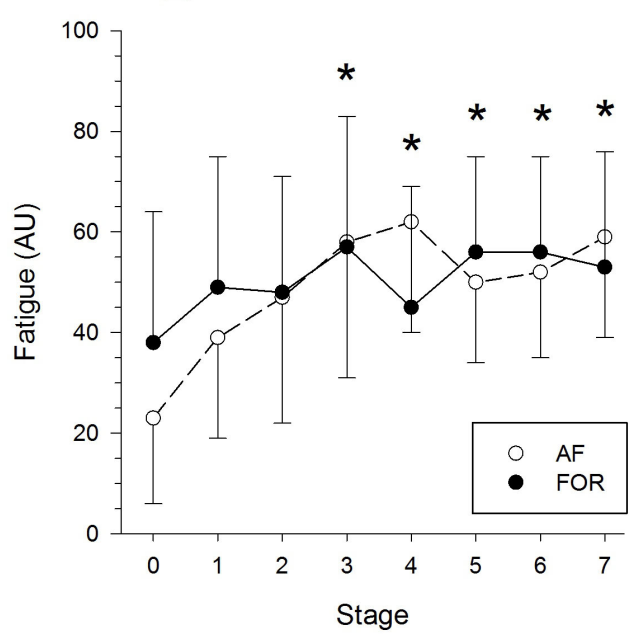

D

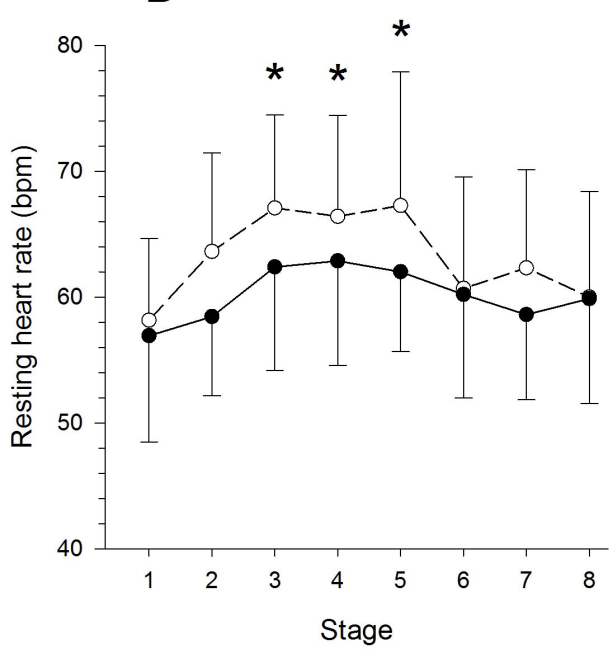

Figure 4 - (A) Readiness to train, (B) fatigue, (C) session rating of perceived exertion, and (D) resting heart rate for acutely fatigued (AF) and functionally overreached (FOR) subjects per stage of the Tour for Life (mean $\pm \mathrm{SD})$. \#Different from FOR. *Different from baseline $(P<.05)$.

At the end of the TFL, change in POMS fatigue and readiness to train (VAS) predicted $75 \%$ of the subjects in the right class (sensitivity $=79 \%$, specificity $=71 \%)$. The sensitivity and specificity were lower for fatigue $(73 \%, 57 \%)$ or readiness $(60 \%, 57 \%)$ individually.

\section{Discussion}

The aim of this study was to investigate whether monitoring of easily measurable stressors and symptoms could be used to distinguish early between AF and FOR. The major result was that the combination of the changes in subjective fatigue and readiness to train, measured on simple visual analog scales, ${ }^{17}$ classified $78 \%$ of the subjects correctly as AF or FOR after only 3 days of cycling.

\section{Classification AF/FOR}

The main reason to distinguish between AF and FOR in this study was that it has been shown in previous work that the supercompensation effect is smaller in FOR than in $\mathrm{AF}^{3,4}$ In accordance with those studies the SWC in performance was used for classification of AF/ FOR in the current investigation. The SWC in our study $(-0.5 \%)$ was of the same magnitude as in the previous work $(-0.6 \%){ }^{3,4}$ Using this method, 15 subjects were classified as FOR and 14 as AF. It is hard to compare these numbers to other investigations because the exercise volume in our study was very high. To illustrate, the total cycling time was twice as high as the total race time of professional cyclists in an 8-day race. ${ }^{24}$ The increase of external training load in our study $(\sim 900 \%)$ was much higher than the generally applied increase in training load by $30 \%$ to $100 \%$. $3,25-27$

FOR precedes NFOR/OTS, the part of the overtraining continuum in which more severe and persistent symptoms occur. So it is possible that some of the FOR athletes in this study developed into the NFOR status. NFOR athletes typically need weeks to months for recovery of performance. ${ }^{1,2}$ On group level the peak power output was probably still lower $(P=.12)$ in FOR compared with AF in the follow-up measurements 5 weeks after TFL (Figure 3). Yet, this measurement was performed near the end of the Dutch amateur roadcycling season. Some subjects did not cycle anymore after the TFL 
while others continued training. Therefore the performance decrement may not be solely related to the effort of TFL. For that reason it was impossible to categorize subjects as FOR or NFOR based on followup performance decrement. Possibly endocrine disturbances ${ }^{19}$ can be used in future research to further categorize FOR/NFOR subjects.

\section{Predictors of FOR}

Fatigue and readiness to train were the best predictors of FOR. Increased perceived fatigue has often been described in FOR athletes. ${ }^{26,28}$ However, to our knowledge, a change in fatigue has not been used before to predict FOR. In our study fatigue was not different between AF and FOR after any of the stages (Figure 4 B). In addition, the sensitivity (67\%) and specificity (36\%) were not

Table 3 Profile of Mood States Subscale Scores (Mean \pm SD)

\begin{tabular}{llccc}
\hline Subscale & & Start & Halfway & End \\
\hline Vigor & AF & $19.0 \pm 2.7$ & $17.6 \pm 4.5$ & $17.1 \pm 3.8$ \\
& FOR & $18.0 \pm 3.3$ & $17.3 \pm 3.5$ & $16.3 \pm 4.4$ \\
& Total & $18.5 \pm 3.0$ & $17.4 \pm 4.0$ & $16.7 \pm 4.1^{\mathrm{a}}$ \\
Anger & AF & $9.6 \pm 3.2$ & $11.3 \pm 5.1$ & $9.2 \pm 2.4$ \\
& FOR & $7.9 \pm 1.5$ & $10.0 \pm 3.2$ & $9.8 \pm 4.1$ \\
& Total & $8.8 \pm 2.6$ & $10.6 \pm 4.2^{\mathrm{a}}$ & $9.5 \pm 3.3$ \\
Fatigue & AF & $8.0 \pm 2.4$ & $16.1 \pm 5.4$ & $13.3 \pm 3.7$ \\
& FOR & $9.1 \pm 4.4$ & $14.3 \pm 4.5$ & $11.9 \pm 3.4$ \\
& Total & $8.6 \pm 3.6$ & $15.1 \pm 5.0^{\mathrm{a}}$ & $12.6 \pm 3.5^{\mathrm{a}, \mathrm{b}}$ \\
Depression & AF & $8.4 \pm 0.8$ & $8.7 \pm 1.1$ & $8.7 \pm 1.6$ \\
& FOR & $8.5 \pm 1.1$ & $9.2 \pm 1.6$ & $9.4 \pm 2.2$ \\
& Total & $8.5 \pm 0.9$ & $9.0 \pm 1.4$ & $9.1 \pm 1.9$ \\
Tension & AF & $10.8 \pm 3.7$ & $7.9 \pm 1.9$ & $6.9 \pm 1.3$ \\
& FOR & $10.4 \pm 3.1$ & $7.1 \pm 1.8$ & $7.1 \pm 1.8$ \\
& Total & $10.6 \pm 3.4$ & $7.5 \pm 1.9^{\mathrm{a}}$ & $7.0 \pm 1.5^{\mathrm{a}}$ \\
\hline
\end{tabular}

Abbreviations: AF, acutely fatigued; FOR, functionally overreached.

${ }^{\mathrm{a}}$ Different from start $(P<.05) .{ }^{\mathrm{b}}$ Different from halfway $(P<.05)$. high when fatigue was the sole predictor of FOR. Yet, the predictive power was substantially improved when combined with changes in readiness to train. Readiness to train is not often mentioned with regard to FOR. Urhausen et $\mathrm{al}^{29}$ showed a significant alteration of readiness for effort in 15 cases of overtraining compared with nonovertraining periods in the same athletes. The overtraining status was not specified because the work was published before the FOR/ NFOR/OTS consensus statement. ${ }^{1}$

Figure 5 shows the individual data points for changes in fatigue and readiness to train. This figure illustrates that a subject who felt less ready for the next stage, while equally fatigued, has a higher chance to become FOR. The combination of change in fatigue and readiness predicted $78 \%$ of the subjects in the correct class. In the study by Urhausen et al. ${ }^{29} 87 \%$ of the cases of overtraining could be recognized by a combination of decreased maximal lactate concentration, maximal heart rate, time to exhaustion, and a selfcondition scale (including readiness for effort). Le Meur et $\mathrm{al}^{25}$ distinguished between athletes who continued their normal training and FOR. They were able to classify $89.5 \%$ of their subjects correctly based on heart rate and lactate concentration during a maximal incremental running test. Subjects who responded well to the overload period (ie, AF) were not included in this discriminant analysis. The sensitivity (79\%) in our study was somewhat lower, but 3 differences between the studies should be taken into account: (1) We distinguished between AF and FOR, while Le Meur et al ${ }^{25}$ distinguished between subjects that continued their normal training and FOR. Based on their figures ${ }^{25}$ the sensitivity would have been considerably lower when a distinction was made between $\mathrm{AF}$ and FOR. (2) We classified subjects after 3 days instead of 3 weeks of exercise. (3) We used 2 visual analog scales instead of a maximal incremental test to predict FOR. These are big advantages for early detection of FOR in training practice.

\section{SRPE, Resting Heart Rate, and POMS}

In contrast to fatigue and readiness to train, other monitoring tools such as the sRPE method, resting heart rate, and POMS (except fatigue) seemed less useful to distinguish between AF and FOR in this study.

sRPE fluctuated per stage whereas fatigue increased progressively during the TFL (Figure 4). Perhaps this indicates that the

Table 4 Predictors Derived From Logistic-Regression Analysis

\begin{tabular}{lccc}
\hline & $\beta($ SE) & OR [95\% Cl] & $P$ \\
\hline Halfway & & & \\
Constant & $-0.54(0.79)$ & & \\
$\Delta$ fatigue (VAS) & $-0.08(0.03)$ & $0.93[0.870 .99]$ & .03 \\
$\Delta$ readiness & $-0.10(0.04)$ & $0.90[0.830 .98]$ & .02
\end{tabular}

Note: $R^{2}=.42$ (Cox \& Snell), .56 (Nagelkerke), model $\chi^{2}{ }_{2}=14.78, P<.01$.

End

Constant

$\Delta$ fatigue (POMS)

$\Delta$ readiness
$0.52(0.65)$

$-0.28(0.14)$

$-0.05(0.02)$
0.76 [0.58 0.99]

$0.95[0.911 .00]$
.04

.04

Note: $R^{2}=.24$ (Cox \& Snell), .32 (Nagelkerke), model $\chi^{2}{ }_{2}=7.79, P=.02$.

Note: Two subjects with multiple missing data were excluded from analysis, resulting in $\mathrm{N}=27$. Abbreviations: OR, odds ratio; VAS, visual analog scale; POMS, Profile of Mood States. 


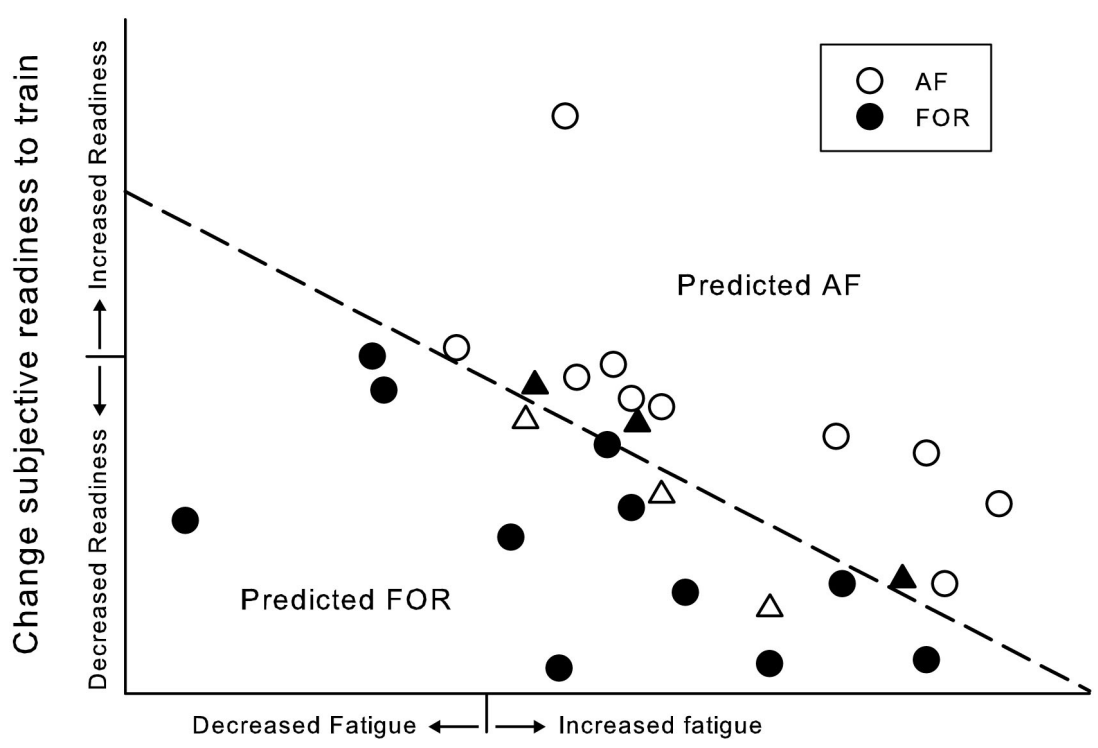

Change subjective fatigue

Figure 5 - Change in subjective fatigue and change in subjective readiness to train for acutely fatigued (AF) and functionally overreached (FOR) subjects. The dashed line represents the demarcation line that follows from the $\beta$ values from the logistic regression. Subjects left/down from the demarcation line are predicted FOR, right/upper predicted as AF. Circles are correctly classified subjects, triangles incorrect classifications. Two subjects with multiple missing data were excluded from logistic-regression analysis, resulting in 27 data points.

sRPE represents only the effort of the specific stage, while subjects integrated accumulated fatigue and recovery in the fatigue score. We speculate that the cumulative fatigue is more relevant than the dayto-day perceived exertion with regard to the development of FOR.

In a meta-analysis it was shown that resting heart rate was increased after intensified training shorter than 2 weeks. ${ }^{6}$ In our study heart rate also increased during the TFL but without differences between the groups. Many factors influence the resting heart rate, such as body position and autonomic activity. ${ }^{30}$ Conditions were difficult to control in this observational field study, in which subjects measured their resting heart rate in their tent at a campsite. This may have resulted in a signal-to-noise ratio too low to pick up differences between the groups.

In this study changes in all POMS subscales (except depression) were observed, but without differences between AF and FOR. The most likely explanation could be in the nature of the TFL, in which many emotions interfered and mood disturbances probably had other causes than FOR. For example, anger increased halfway through the event, perhaps due the intensive contact between team members. In addition, tension was highest at the start of the TFL, perhaps because the riders did not exactly know what to expect or if they could make it to the finish. Micklewright et $\mathrm{al}^{31}$ showed that performance expectations influence postrace mood. This suggests that monitoring mood might not be suitable in exceptional races such as TFL.

\section{Practical Applications}

This study shows that monitoring both the changes in fatigue and readiness to train, using simple visual analog scales, can be used to early distinguish between FOR and AF. Hence, we encourage athlete support staff to not only monitor fatigue, but also the subjective integrated mental and physical readiness to perform of their athletes. Monitoring of these factors is easily applied in training practice, it is not demanding for athletes and can be implemented with minimal costs.

This study was conducted in a specific natural model involving recreational athletes experiencing an enormous increase in training load. Further research should focus on application to high-level and elite athletes in their normal training cycles. In addition, prolonged monitoring of changes in fatigue and readiness is advised.

\section{Conclusion}

This study shows that monitoring of easy measurable symptoms can be used to identify FOR after only 3 days of cycling. Monitoring changes in fatigue and readiness to train, using simple visual analog scales, had the highest predictive power to identify FOR.

\section{Acknowledgments}

The study was performed by the Ambruro consortium, an acronym for its partners Vrije Universiteit Amsterdam, Vrije Universiteit Brussels, UMC Utrecht, Università degli Studi di Roma Foro Italico. Led by the Vrije Universiteit Amsterdam the consortium designed and conducted the Ambruro training monitor study, of which part of the results are described in this paper.

We are very grateful to all participants who showed up for all measurements despite the physical and mental stress of the TFL. In addition, we would like to thank Tour for Life organizer Emolife, especially Nienke Wynia and Kelian Lankester, for their collaboration. Not the least, thanks to Danilo Iannetta, Erinke van Grinsven, Eva Peters, Geert Janszen, Hans de Koning, Ineke Nederend, Jelle de Jong, Karlijn te Poele, Kristel Piets, Leo Houben, Linda van der Meijden, Loek Vossen, Margot Klöpping, Querian Eijgensteijn, Rene van Lien, Silvan Buis, and Wouter Ruchtie for their enthusiastic help with the data collection. 


\section{References}

1. Meeusen R, Duclos M, Gleeson M, Rietjens G, Steinacker J, Urhausen A. Prevention, diagnosis and treatment of the overtraining syndrome. Eur J Sport Sci. 2006;6(1):1-14. doi:10.1080/17461390600617717

2. Meeusen R, Duclos M, Foster C, et al. Prevention, diagnosis, and treatment of the overtraining syndrome: joint consensus statement of the European College of Sport Science and the American College of Sports Medicine. Med Sci Sports Exerc. 2013;45(1):186-205. PubMed doi:10.1249/MSS.0b013e318279a10a

3. Aubry A, Hausswirth C, Louis J, Coutts AJ, Le Meur Y. Functional overreaching: the key to peak performance during the taper? Med Sci Sports Exerc. 2014;46(9):1769-1777. PubMed doi:10.1249/ MSS.0000000000000301

4. Aubry A, Hausswirth C, Louis J, Coutts AJ, Buchheit M, Le Meur Y. The development of functional overreaching is associated with a faster heart rate recovery in endurance athletes. PLoS One. 2015;10(10):e0139754. PubMed doi:10.1371/journal.pone.0139754

5. Hausswirth C, Louis J, Aubry A, Bonnet G, Duffield R, Le Meur Y. Evidence of disturbed sleep and increased illness in overreached endurance athletes. Med Sci Sports Exerc. 2014;46(5):1036-1045. PubMed doi:10.1249/MSS.0000000000000177

6. Bosquet L, Merkari S, Arvisais D, Aubert AE. Is heart rate a convenient tool to monitor over-reaching?: a systematic review of the literature. Br J Sports Med. 2008;42(9):709-714. PubMed doi:10.1136/ bjsm.2007.042200

7. Brink MS, Visscher C, Arends S, Zwerver J, Post WJ, Lemmink KA. Monitoring stress and recovery: new insights for the prevention of injuries and illnesses in elite youth soccer players. Br J Sports Med. 2010;44(11):809-815. PubMed doi:10.1136/bjsm.2009.069476

8. Comotto S, Bottoni A, Moci E, Piacentini MF. Analysis of session-RPE and profile of mood states during a triathlon training camp. J Sports Med Phys Fitness. 2015;55(4):361-367. PubMed

9. Le Meur Y, Buchheit M, Aubry A, Coutts AJ, Hausswirth C. Assessing overreaching with HRR: what is the minimal exercise intensity required [published online ahead of print September 6, 2016]? Int J Sports Physiol Perform. doi:10.1123/ijspp.2015-0675 PubMed

10. Halson SL. Monitoring training load to understand fatigue in athletes. Sports Med. 2014;44(Suppl 2):S139-S147. PubMed doi:10.1007/ s40279-014-0253-z

11. Foster C, Hector LL, Welsh R, Schrager M, Green MA, Snyder AC. Effects of specific versus cross-training on running performance. Eur J Appl Physiol Occup Physiol. 1995;70(4):367-372. PubMed doi:10.1007/BF00865035

12. Armstrong LE, VanHeest JL. The unknown mechanism of the overtraining syndrome: clues from depression and psychoneuroimmunology. Sports Med. 2002;32(3):185-209. PubMed doi:10.2165/00007256-200232030-00003

13. De Pauw K, Roelands B, Cheung SS, De Geus B, Rietjens G, Meeusen R. Guidelines to classify subject groups in sport-science research. Int J Sports Physiol Perform. 2013;8(2):111-122. PubMed doi:10.1123/ ijspp.8.2.111

14. Decroix L, De Pauw K, Foster C, Meeusen R. Guidelines to classify female subject groups in sport science research. Int J Sports Physiol Perform. 2016;11(2):204-213. PubMed doi:10.1123/ijspp.2015-0153

15. Jones NL, Makrides L, Hitchcock C, Chypchar T, McCartney N. Normal standards for an incremental progressive cycle ergometer test. Am Rev Respir Dis. 1985;131(5):700-708. PubMed
16. Christen J, Foster C, Porcari JP, Mikat RP. Temporal robustness of the session rating of perceived exertion. Int J Sports Physiol Perform. 2016;11(8):1088-1093. http://dx.doi.org/10.1123/ijspp.2015-0438

17. Piacentini MF, Meeusen R. An online training-monitoring system to prevent nonfunctional overreaching. Int J Sports Physiol Perform. 2015;10(4):524-527. PubMed doi:10.1123/ijspp.2014-0270

18. Wald FDM, Mellenbergh GJ. De verkorte versie van de Nederlandse vertaling van de Profile of Mood States (POMS). Ned Tijdschr Psychol. 1990;45:86-90.

19. Meeusen R, Piacentini MF, Busschaert B, Buyse L, De Schutter G, Stray-Gundersen J. Hormonal responses in athletes: the use of a two bout exercise protocol to detect subtle differences in (over) training status. Eur J Appl Physiol. 2004;91(2-3):140-146. PubMed doi:10.1007/s00421-003-0940-1

20. Foster C. Monitoring training in athletes with reference to overtraining syndrome. Med Sci Sports Exerc. 1998;30(7):1164-1168. PubMed doi:10.1097/00005768-199807000-00023

21. Kenttä G, Hassmén P, Raglin JS. Mood state monitoring of training and recovery in elite kayakers. Eur J Sport Sci. 2006;6(4):245-253. doi:10.1080/17461390601012652

22. Hopkins WG, Hawley JA, Burke LM. Design and analysis of research on sport performance enhancement. Med Sci Sports Exerc. 1999;31(3):472_ 485. PubMed doi:10.1097/00005768-199903000-00018

23. Hopkins WG, Marshall SW, Batterham AM, Hanin J. Progressive statistics for studies in sports medicine and exercise science. Med Sci Sports Exerc. 2009;41(1):3-13. PubMed doi:10.1249/ MSS.0b013e31818cb278

24. Rodríguez-Marroyo JA, García-López J, Juneau C-E, Villa JG. Workload demands in professional multi-stage cycling races of varying duration. Br J Sports Med. 2009;43(3):180-185. PubMed doi:10.1136/ bjsm.2007.043125

25. Le Meur Y, Hausswirth C, Natta F, Couturier A, Bignet F, Vidal PP. A multidisciplinary approach to overreaching detection in endurance trained athletes. J Appl Physiol. 2013;114(3):411-420. PubMed doi:10.1152/japplphysiol.01254.2012

26. Dupuy O, Lussier M, Fraser S, Bherer L, Audiffren M, Bosquet L. Effect of overreaching on cognitive performance and related cardiac autonomic control. Scand J Med Sci Sports. 2014;24(1):234-242. PubMed

27. Nederhof E, Lemmink KAPM, Zwerver J, Mulder T. The effect of high load training on psychomotor speed. Int J Sports Med. 2007;28(7):595-601. PubMed doi:10.1055/s-2007-964852

28. Le Meur Y, Pichon A, Schaal K, et al. Evidence of parasympathetic hyperactivity in functionally overreached athletes. Med Sci Sports Exerc. 2013;45(11):2061-2071. PubMed doi:10.1249/ MSS.0b013e3182980125

29. Urhausen A, Gabriel HHW, Weiler B, Kindermann W. Ergometric and psychological findings during overtraining: a long-term follow-up study in endurance athletes. Int J Sports Med. 1998;19(2):114-120. PubMed doi:10.1055/s-2007-971892

30. Buchheit M. Monitoring training status with HR measures: do all roads lead to Rome? Front Physiol. 2014;5:73. PubMed doi:10.3389/ fphys.2014.00073

31. Micklewright D, Papadopoulou E, Parry D, Hew-Butler T, Tam N, Noakes T. Perceived exertion influences pacing among ultramarathon runners but post-race mood change is associated with performance expectancy. South Afr J Sport Med. 2009;21(4):167-172. doi:10.17159/2078-516X/2009/v21i4a290 